\title{
Dynamic Study of Feed-Effluent Heat Exchanger Addition on Double Bed Configuration Ammonia Reactor System within Varied Quenching Ratio
}

\author{
Tri Partono Adhi ${ }^{1, *}$, Ferdyan Ihza Akbar $^{1}$ \\ ${ }^{1}$ Institut Teknologi Bandung, Chemical Engineering Department, 40135 Bandung, Indonesia
}

\begin{abstract}
Ammonia is one of the most important industrial commodity due to its wide function. Ammonia synthesis reaction is an exotermic reaction. Therefore, Feed-Effluent Heat Exchanger (FEHE) is added to increase thermal efficiency. However, FEHE could lead the process to experience hysteresis phenomenon due to interaction between equipments as one steady state $\mathrm{T}$ feed could result several $\mathrm{T}$ outlet. Hysteresis phenomenon may result asset losses like explosion, leakage, and loosing material integrity. Double bed reactor configuration allows us to use several operating parameters as variation to overcome hysteresis. In this review, quenching ratio was chosen to be that varied parameter. This study aims to determine how quenching ratio affects hysteresis zone by utilizing Aspen Hysys ${ }^{\circledR}$ V8.8 as simulation tool. Simulation showed that quenching ratio would narrow hysteresis zone yet increased extinction temperature that lower the conversion. Conversion profile showed that 0.2 quenching ratio got the highest conversion for system with bed volume ratio $2: 1$ while total volume was $30 \mathrm{~m}^{3}$. However, the feed temperature was fallen at hysteresis zone. Dynamic simulation showed that highest conversion feed temperature $(10 \% \Delta \mathrm{Tf}$ above extinct temperature) was still able to preserve stability with descending temperature approach. Hysteresis itself started to occur at $1.7 \% \Delta \mathrm{Tf}$ above extinct temperature
\end{abstract}

\section{Introduction}

Ammonia is one of important industrial commodity due to its wide utilization as chemical product precursor such as urea, nitric acid, and etc. In ammonia production system, Feed-Effluent Heat Exchanger (FEHE) is commonly used that aims to exchange heat between reactor effluent and reactor feed as shown in Fig. 1.

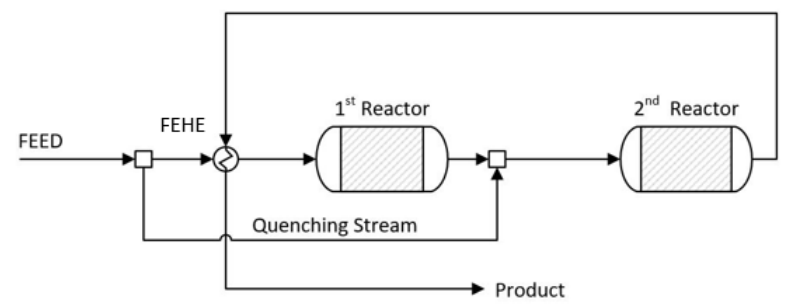

Fig. 1. Ammonia reactor system configuration

Such heat integration system would reduce utility requirement and increase thermal efficiency. However, the integration system could possibly lead the process system to experience significant temperature oscillation as shown in Fig. 2. Oscillations occur as the result of two or more processes that are coupled together with each other [1,7]. In this case, reactors performance is closely related to how the FEHE performs. As the result, reactor possibly undergoes a phenomenon while same operating condition could produce several steady state outputs that lead the process to oscillate $[1,6]$. This condition could cause several hazards for the equipment material and even operational staff $[4,5]$. Hazards that occurred could dangerously result disasters such as explosion or poisoneous chemical leakage which causing economic losses.

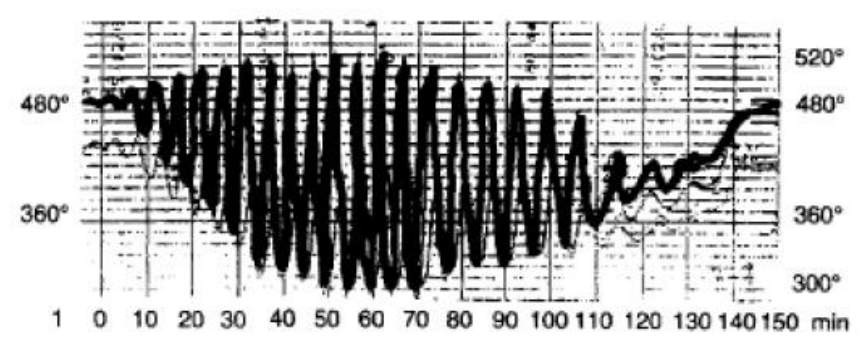

Fig. 2. Hysteresis phenomenon on industrial scale ammonia reactor. [3]

Hysteresis area could be predicted by plotting one of steady state parameter such (T outlet) as result of $\mathrm{T}$ feed input as shown in Fig. 3.

\footnotetext{
Corresponding author: tpadhi@che.itb.ac.id
} 


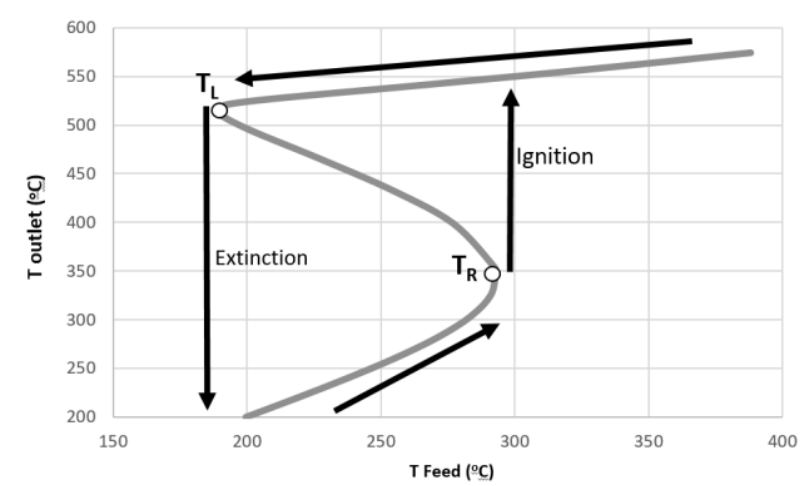

Fig. 3. Curve plot to determine hysteresis zone

The ' $S$ ' curve produced showed that within range of $T_{L}$ and $T_{R}\left(\Delta T_{f}\right)$, each $T$ feed input will result several values of $\mathrm{T}$ outlet. Therefore, there will be possibility for the process to experience oscillation while entering this region.

Some efforts to deal with this condition could be done by changing other supporting operation parameter for double bed system such as adding trim heat exchanger, bed volume distribution, or quenching ratio.
Therefore, this study would show parametric review and simulation regarding actions to overcome and reduce hysteresis phenomenon by choosing quenching ratio as varied operation parameter. As the quenching ratios were evaluated, conversion profile was also analyzed to map the best temperature at particular quenching ratio to produce optimum reactant conversion. As the matter of limitting the problem, this review focused on observing feed temperature, outlet reactor temperature, quenching ratio, reactant conversion, and starting hysteresis temperature.

\section{Methods}

Aspen Hysys ${ }^{\circledR}$ V8.8 were used to act as an assistive tools for simulating the dynamic behaviour resulted from altered parameter value. Simulation configuration is shown in Fig. 4.

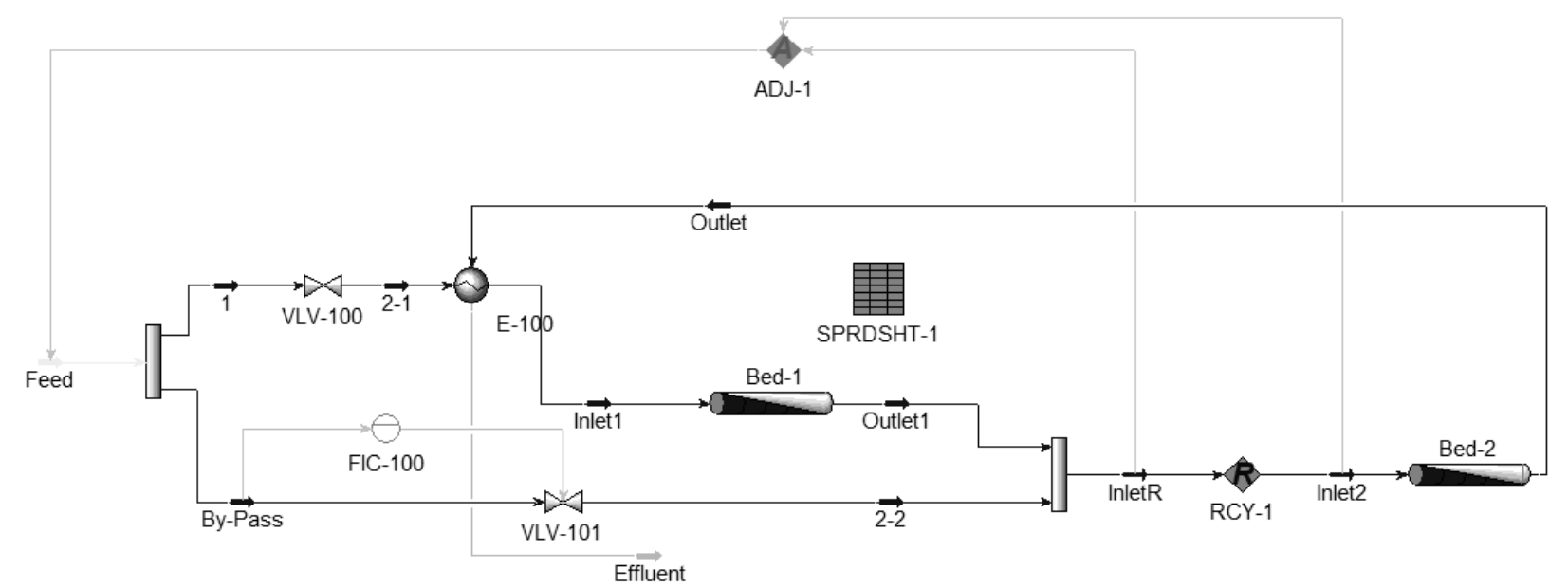

Fig. 4. Simulation Configuration

Fluid package used in the simulation was PengRobinson. Ammonia reaction kinetics behaviour for calculation was based on following equation [2] .

$$
\begin{gathered}
N_{2}+H_{2} \leftrightarrow N_{3} \\
r=23.618 \exp \left(-\frac{87,090}{R T}\right) \frac{P_{N 2} P_{H 2}^{l .5}}{P_{N H 3}} \\
-3.39 \times 10^{13} \exp \left(-\frac{198,460}{R T}\right) \frac{P_{N H 3}}{P_{H 2}^{1.5}}
\end{gathered}
$$

Plug Flow Reactor (PFR) with total volume $30 \mathrm{~m}^{3}$ was used in the simulation. Quenching process was simulated by using splitter and mixer features of Aspen Hysys ${ }^{\circledR}$ V8.8. Quenching ratio was varied with assumed $1^{\text {st }}$ bed volume at $20 \mathrm{~m}^{3}$ and $2^{\text {nd }}$ bed at $10 \mathrm{~m}^{3}$. FEHE simulation was conducted with steady-state-rating mode and sized rigorously by using interactive mode to obtain certain characteristic on heat transfer. FEHE specification sheet is shown in Table 1.
Hysteresis zone identification was conducted by using Adjust feature on Aspen Hysys ${ }^{\circledR}$ V8.8. This process was done by varying the $2^{\text {nd }}$ reactor inlet temperature to adjust the feed temperature on each quenching ratio. This attempt eventually would result plot T Feed vs T Outlet correlation to identify hysteresis zone. Reactant conversion was then identified by using Case Study feature on Aspen Hysys ${ }^{\circledR}$ V8.8. This study was done by varying feed temperature on each quenching ratio or bed volume distribution and observing the mole flow of the ammonia in the outlet stream. At the end, Aspen Hysys ${ }^{\circledR}$ V8.8 Dynamic feature was conducted to observe the process dynamic behaviour at quenching ratio which resulted highest reactant conversion. Eventually, dynamic observation was used to determine starting temperature of oscillation as the percentage of $\Delta \mathrm{T}_{\mathrm{f}}$. Dynamic simulation was also used to determine process stability while feed temperature was set at value that resulted highest conversion in chosen quenching ratio. 
Table 1. FEHE Specification Sheet.

\begin{tabular}{|c|c|c|c|}
\hline Specification & Value & Specification & Value \\
\hline TEMA & AEL & $\begin{array}{l}\text { Shell Diameter } \\
(\mathrm{mm})\end{array}$ & 818.85 \\
\hline $\begin{array}{c}\text { Number of } \\
\text { Shell per Pass }\end{array}$ & 1 & $\begin{array}{c}\text { Number of Tube } \\
\text { per Shell }\end{array}$ & 872 \\
\hline $\begin{array}{c}\text { Number of } \\
\text { Shell in Series }\end{array}$ & 1 & Tube Pitch (mm) & 23.81 \\
\hline $\begin{array}{c}\text { Number of } \\
\text { Shell in Parallel }\end{array}$ & 2 & $\begin{array}{c}\text { Tube Layout } \\
\text { Angle }\end{array}$ & $\begin{array}{l}\text { Triangl } \\
\text { uar } \\
(30 \mathrm{o})\end{array}$ \\
\hline $\begin{array}{c}\text { Tube Passes } \\
\text { per Shell }\end{array}$ & 1 & $\begin{array}{c}\text { Shell Fouling } \\
\text { Factor }\left({ }^{\circ} \mathrm{C} \mathrm{m} 2 / \mathrm{kJ}\right)\end{array}$ & $\begin{array}{c}0.00002 \\
8 \\
\end{array}$ \\
\hline Orientation & $\begin{array}{l}\text { Horizon } \\
\text { tal }\end{array}$ & Baffle Type & Single \\
\hline $\begin{array}{l}\text { First tube pass } \\
\text { flow direction }\end{array}$ & Counter & Baffle Orientation & $\begin{array}{l}\text { Horizon } \\
\text { tal }\end{array}$ \\
\hline Elevation & 0 & $\begin{array}{l}\text { Baffle Cut } \\
\text { (\%Height) }\end{array}$ & 20.00 \\
\hline $\begin{array}{c}\text { Shell HT coeff. } \\
\left(\mathrm{kJ} / \mathrm{m}^{2}{ }^{\circ} \mathrm{C}\right)\end{array}$ & 8908 & $\begin{array}{l}\text { Baffle Spacing } \\
(\mathrm{mm})\end{array}$ & 800.00 \\
\hline $\begin{array}{c}\text { Tube HT coeff. } \\
\left(\mathrm{kJ} / \mathrm{m}^{2}{ }^{\circ} \mathrm{C}\right)\end{array}$ & 12304 & Tube OD (mm) & 19.050 \\
\hline $\begin{array}{l}\text { Overall U } \\
\left(\mathrm{kJ} / \mathrm{m}^{\circ}{ }^{\circ} \mathrm{C}\right)\end{array}$ & 2604 & Tube ID (mm) & 10.668 \\
\hline $\begin{array}{l}\text { Overall UA } \\
\left(\mathrm{kJ} / \mathrm{m}^{2}{ }^{\circ} \mathrm{C}\right)\end{array}$ & 101900 & $\begin{array}{l}\text { Tube Thickness } \\
\text { (mm) }\end{array}$ & 4.191 \\
\hline $\begin{array}{l}\text { Shell pressure } \\
\text { drop (bar) }\end{array}$ & 0.5855 & Tube Length (m) & 3.750 \\
\hline $\begin{array}{l}\text { Tube pressure } \\
\text { drop (bar) }\end{array}$ & 0.1386 & $\begin{array}{c}\text { Tube Fouling } \\
\text { Factor }\left({ }^{\circ} \mathrm{C} \mathrm{m} 2 / \mathrm{kJ}\right)\end{array}$ & $\begin{array}{c}0.00002 \\
8\end{array}$ \\
\hline $\begin{array}{l}\text { Heat transfer } \\
\text { area per shell } \\
\left(\mathrm{m}^{2}\right)\end{array}$ & 195.7 & $\begin{array}{l}\text { Themal cond. } \\
\qquad(\mathrm{W} / \mathrm{mK})\end{array}$ & 45 \\
\hline $\begin{array}{l}\text { Tube volume } \\
\text { per shell }\left(\mathrm{m}^{3}\right)\end{array}$ & 0.2923 & $\begin{array}{c}\text { Wall Heat } \\
\text { Capacity Coeff. } \\
(\mathrm{kJ} / \mathrm{kg} \mathrm{C})\end{array}$ & 0.473 \\
\hline $\begin{array}{l}\text { Shell volume } \\
\text { per shell }\left(\mathrm{m}^{3}\right)\end{array}$ & 1.043 & $\begin{array}{c}\text { Wall Density } \\
(\mathrm{kg} / \mathrm{m} 3)\end{array}$ & 7801 \\
\hline
\end{tabular}

\section{Results}

Unstable process as the result of FEHE utilization in double bed reactor is possible to create instability zone like the one in single bed configuration. Identified instability zone study resulted from varied quenching ratio and bed volume distribution of double bed reactor would be explained in the following section.

\subsection{Hysteresis Zone Alteration Due to Varied Quenching Ratio}

Fig. 5 shows that generally higher quenching ratio would lead to more narrow hysteresis but higher extinct temperature.

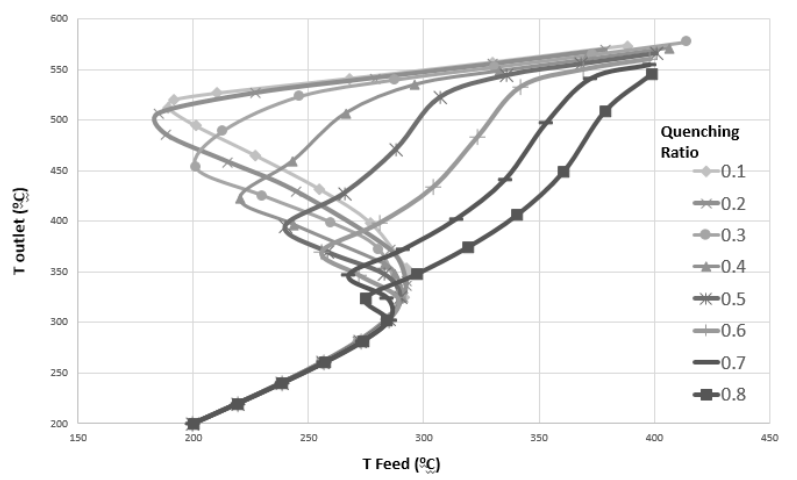

Fig. 5. Hysteresis zone alteration on varied quenching ratio

Higher extinct temperature could possibly lead the reaction to easily extincted and furthermore it would result lower reactant conversion. At bed volume distribution of $2: 1$, hysteresis zone experienced trend of rise from 0.1 to 0.2 and drop from $0.2-0.8$. From here, there was an observed reversed trend at 0.2 quenching ratio. This possibly indicates that there was optimum point regarding the process parameter related to feed or outlet temperature. Closest relation to these parameters was conversion profile of the reaction. Reactant conversion was then evaluated from each quenching ratio at steady state simulation as shown in Fig. 6.

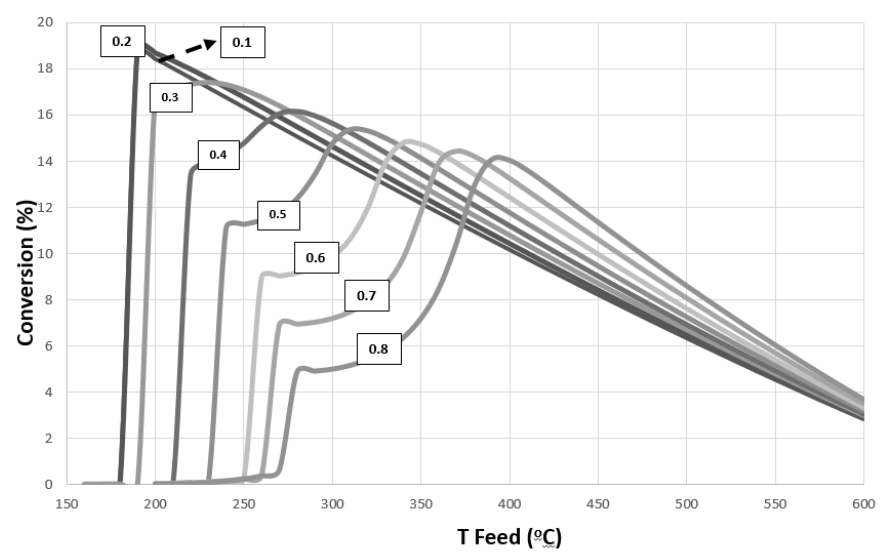

Fig. 6. Conversion profile on varied quenching ratio with $1^{\text {st }}$ bed volume $=20 \mathrm{~m}^{3}$

Fig. 6 shows that generally lower quenching ratio will increase the conversion and it shows highest overall conversion profile at 0.2 quenching ratio. Optimum point of conversion profile at each quenching ratio was then plotted as shown at Fig. 7. 


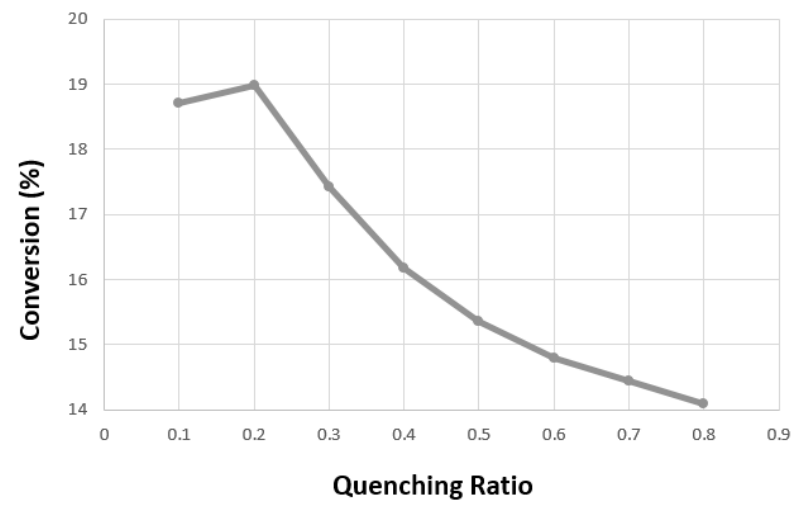

Fig. 7. Highest conversion plot at each quenching ratio

Fig. 7 shows that quenching ratio 0.2 resulted highest conversion which is $18.97 \%$ at bed volume distribution $2: 1$. This is the equilbrium conversion and obtained at $\mathrm{T}$ feed $=190^{\circ} \mathrm{C}$. However, this temperature was located inside the hysteresis zone and was close to the 0.2 quenching ratio extinct temperature which was $184.69^{\circ} \mathrm{C}$. Therefore, dynamic simulation then was conducted to determine the stability behaviour at $190^{\circ} \mathrm{C}$ as the operation is basically purposed to achieve conversion requirement as high as possible.

\subsection{Dynamic Simulation}

In this section, Aspen Hysys® V8.8 Dynamic Mode feature was utilized to identify stable/unstable behaviour in real time. From Fig. 5, we know that extinct temperature is $184.69^{\circ} \mathrm{C}$ at 0.2 quenching ratio. Hence, utilizing Dynamic Mode could possibly show minimum temperature to start hysteresis (as function of $\Delta \mathrm{T}_{\mathrm{f}}=$ $107.62^{\circ} \mathrm{C}$ ) before the oscillation extinct the reaction. Dynamic Mode was started with ingniting the reaction by set the $\mathrm{T}$ feed to $300^{\circ} \mathrm{C}$ (refer to Fig. 8). T feed was then lowered steppedly to $200^{\circ} \mathrm{C}$ and then $190^{\circ} \mathrm{C}$. Starting from this point, feed temperature was lowered rampedly by $0.1^{\circ} \mathrm{C}$ to find the hysteresis minimum temperature as accurate as possible. Dynamic simulation showed that oscillation phenomenon started at $186.6^{\circ} \mathrm{C}$. This means that at 0.2 quenching ratio and bed volume distribution 2:1, hysterisis mathematically will start approximately at:

$$
T \text { feed hysteresis }=T \text { extinction }+1.77 \%\left(\Delta T_{f}\right)
$$

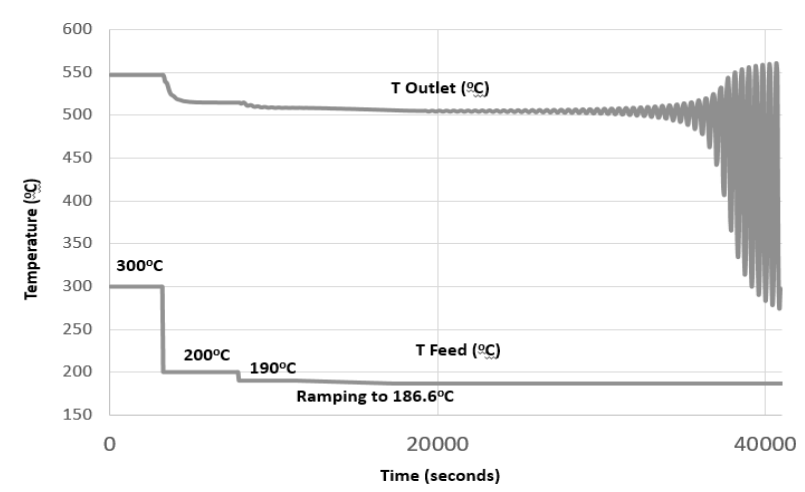

Fig. 8. Minimum hysteresis temperature determination at 0.2 quenching ratio
Highest conversion while applying 0.2 quenching ratio and bed volume distribution 2:1 was obtained at $190^{\circ} \mathrm{C}$. Mathematically this point was formulated as:

$$
\text { Tfeed highest conversion }=T \text { feed }+5 \%\left(\Delta T_{f}\right)
$$

Therefore, this feed temperature was tested in Dynamic Mode to measure whether the highest conversion could be achieved stably. Result is shown in Fig. 9. Referring to Fig 9, we are able to conclude that highest conversion of the reaction (at bed volume distribution 2:1) could be achieved stably.

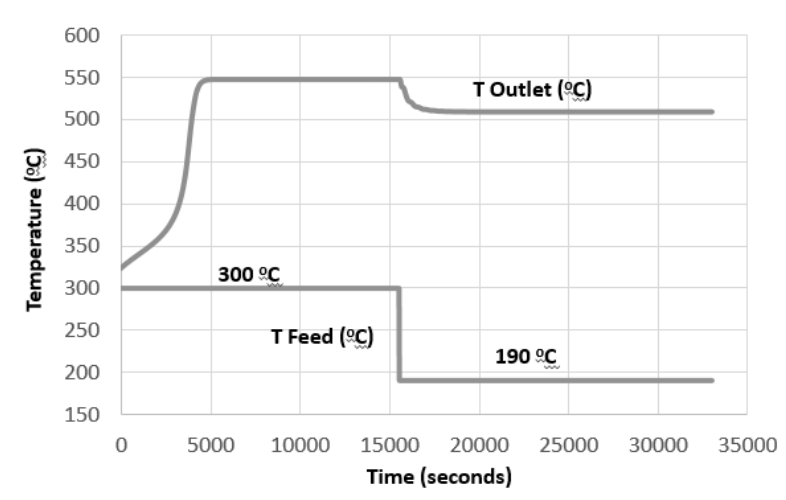

Fig. 9. Stability identification at highest conversion feed temperature $\left(190^{\circ} \mathrm{C}\right)$

\section{Conclusion}

Quenching ratio alteration could affect how wide the hysteresis area is while plotting $\mathrm{T}$ outlet vs $\mathrm{T}$ feed. Higher quenching ratio showed narrowing hysteresis yet increase the extinct temperature that could lower the conversion. Highest conversion was obtained at 0.2 quenching ratio (bed volume distribution 2:1) with $\mathrm{T}$ feed $=190^{\circ} \mathrm{C}$ which entering the hysteresis zone. However, this condition was chosen to be analyzed more in the Dynamic Mode to determine whether $190^{\circ} \mathrm{C}$ would already triggered the oscillation. Dynamic Mode showed that oscillation started at $186.6^{\circ} \mathrm{C}$ and further extinct the reaction. The highest conversion feed temperature was then tested in Dynamic Mode and resulted stable operation. Therefore, while using bed volume distribution 2:1 (total volume $=30 \mathrm{~m}^{3}$ ), ammonia reaction highest conversion of $18.97 \%$ (quenching ratio $=0.2$ ) is still able to be obtained at stable operation.

\section{References}

1. B. A. Finlayson, ACS Symposium Series, 65, 1 (1978)

2. G. R. Setyadi \& T. P. Adhi, Dynamic Simulation Adiabatic Extothermal Reactor with addition of FEHE, Thesis of ITB Chemical Engineering Department (2005)

3. J. C. Morud \& S. Skogestad, AIChE.J, 44, 888-895 (1988) 
4. J.R. Rouse \& C. Hyde, Materials (Basel) 9, 1 (2016)

5. P. Laššak, J. Labovský, Ĺ. Jelemenský, Journal of Loss Prevention in the Process Industries, 23, 2, $280-288$ (2010).

6. R. K. Herz, Chemical Reaction Engineering-Part 15-CSTR Thermal Effects, SS + Dynamic, University of California San Diego, 15, 5 (2015) 